\title{
Analisis Spektrum Energi dan Fungsi Gelombang Potensial Non-Sentral Poschl-Teller Termodifikasi plus Potensial Scarf Trigonometri Menggunakan Persamaan Hipergeometri
}

\author{
Suparmi, Cari, Hadma Yuliani, Dwi Yuniati \\ Universitas Sebelas Maret, \\ Jl. Ir. Sutami no 36A Kentingan Surakarta 57126. Ph. 646994, 636895. Fax.646655 \\ E-mail:suparmiuns@gmail.com
}

\begin{abstract}
Abstrak - Spektrum energi dan fungsi gelombang untuk potensial non-sentral dianalisis secara intensif. Persamaan hipergeometri digunakan untuk menganalisa spektrum energi dan fungsi gelombang untuk potensial non-sentral Poschl-Teller termodifikasi dan Scarf II trigonometri. Spektrum energi dan fungsi gelombang radial yang diperoleh hanya bersifat pendekatan karena dimasukkannya faktor sentrifugal dan diperoleh dari persamaan Schrodinger bagian radial, sedangkan fungsi gelombang bagian sudut dan bilangan kuantum orbital diperoleh dari persamaan Schrodinger bagian sudut. Fungsi gelombang bagian radial dan bagian sudut yang diperoleh dinyatakan dalam polinomial hipergeometri.
\end{abstract}

Kata Kunci : Persamaan Schrodinger, spektrum energi, fungsi gelombang, potensial non-sentral, Poschl-Teller termodifikasi plus scarf II trigonometri, persamaan hipergeometri.

\begin{abstract}
Energy spectrum and wave function of non-central potential is recently investigated intensively. The hypergeometric equation is used to analyze the energy spectrum and energy wave function of non-central potential as combination of modified Poschl-Teller radial potential with trigonometric Scarf non-central potential. The energy spectrum and the radial wave function are obtained approximately due to the centrifugal term from the radial Schrodinger equation and expressed in the closed form, while the angular wave function and the orbital quantum number are obtained from angular Schrodinger equation. The approximate radial wave function and angular wave function are expressed in terms of hypergeometric polynomials.
\end{abstract}

Key words: Schrodinger Equation, energy spectrum, wave function, non-central potential, modified Poschl-Teller plus trigonometric Scarf II, hypergeometric equation

\section{PENDAHULUAN}

Persamaan Schrodinger (PS) merupakan jantung dalam mekanika kuantum. Energi dan fungsi gelombang suatu sistem partikel yang diperoleh dari penyelesaian persamaan Schrodinger secara langsung dari sistem partikel, digunakan untuk mendiskripsikan perilaku sekelompok partikel. Persaman Schrodinger untuk sistem partikel yang dipengaruhi oleh potensial dengan energi potensial yang merupakan fungsi posisi yang agak kompleks biasanya diselesaikan dengan cara mereduksi persamaan Schrodinger menjadi persamaan diferensial orde dua fungsi khusus seperti fungsi Hermite, Legendre, Laguerre, hipergeometri atau confluent hypergeometry dengan substitusi variabel yang sesuai [1]. Namun diantara fungsi-fungsi tersebut, hanya persamaan diferensial fungsi Hipergeometri atau Confluent Hypergeometry $(\mathrm{H}-\mathrm{CH})$ yang merupakan penyelesaian yang paling umum karena persamaan diferensial fungsi khusus yang lain seperti Hermite, Legendre, atau Laguerre dapat direduksi menjadi persamaan diferensial H-CH [2].

Persamaan Schrodinger (PS) untuk potensial yang merupakan fungsi hiperbolik, eksponensial dan trigonometrik seperti Poschl-Teller [1,3,4,5,6,7], Scarf $[1,3,8]$, Morse [1,3], Rosen-Morse [1,3,5,11], Wood-Saxon $[1,3,9]$, Eckart $[1,3,10]$, Hulthen $[1,3]$ dapat diselesaikan dengan menggunakan SUSY MK [1,3,11], Nikivarov Ufarov (NU) [12,13] dan persamaan hipergeometri [1]. Namun aplikasi persamaan hipergeometri lebih luas dari pada SUSY MK karena dapat digunakan untuk menyelesaiakan PS potensial baik shape invariance (SI) dan non-shape invariance (NSI) sedangkan SUSY MK hanya untuk potensial shape invariance saja.[14]

Persamaan Schrodinger untuk potensial sentral telah banyak didiskusikan dalam buku MK seperti potensial Coulomb, Morse, potensial harmonik osilator tiga dimensi, Hulthen, dll. [15, 1]. Potensial sentral adalah potensial yeng mempunyai energi potensial yang hanya merupakan fungsi jarak antara partikel yang dikaji dengan titik yang merupakan sumber potensial (gaya) yang mempengaruhi partikel tersebut. Untuk potensial non-sentral, energi potensialnya merupakan fungsi jarak dan sudut sekaligus. Potensial Coulombic -Poschl-Teller non-sentral adalah salah satu potensial non-sentral yang mempengaruhi gerak sebuah elektron yang terikat dengan inti yang mana elektron 
berotasi terhadap inti sambil melakukan gerak periodik dalam lintasan rotasinya. Potensial non-sentral adalah kombinasi dari potensial SI atau NSI, baik fungsi hiperbolik, eksponensial dan trigonometrik, yang merupakan fungsi radial saja dengan potensial SI trigonometrik yang merupakan fungsi radial dan sudut. [non-sentral, Makarov]

\section{METODE PENELITIAN/EKSPERIMEN}

Potensial Non-Sentral Poschl-Teller Termodifikasi plus Potensial Scarf Trigonometri Menggunakan Persamaan Hipergeometri

\section{HASIL DAN PEMBAHASAN}

\subsection{Review persamaan diferensial orde dua fungsi hipergeometri}

Persamaan Schrodinger satu dimensi untuk sistem kuantum yang dipengaruhi oleh medan dengan energi potensial $F(x)$ dapat dituliskan sebagai

$$
-\frac{\hbar^{2}}{2 v s} \frac{d^{2} \psi(x)}{d x^{2}}+P(\alpha) \psi(\alpha)=B \psi(x)
$$

Persamaan Schrodinger satu dimensi untuk potensial shape invariance dapat diubah (direduksi) menjadi persamaan diferensial orde dua fungsi hipergeometri atau confluent hypergeometry dengan substitusi variabel yang sesuai. Dengan substitusi variabel yang sesuai, $x=f(s)$. persamaan Schrodinger pada pers. (1) berubah menjadi persamaan perantara hipergeometri (PPH) sebagai

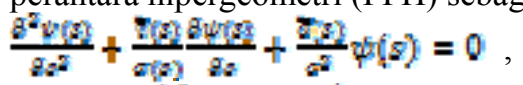

dengan $\sigma(s)$ and $\overline{\boldsymbol{v}}(s)$ merupakan polynomial yang pada umumnya berderajat dua, sedangkan if(s) merupakan polynomial berderajat satu, yang masing-masing dinyatakan yang dinyatakan sebagai

$\sigma(s)=a s^{2}+b s+c$ dan $\bar{\tau}(s)=d s+\epsilon$

Persamaan (2) diubah menjadi persamaan hipergeometri dengan mengasumsikan bentuk penyelesaian dari persamaan (2) adalah

$$
\psi(s)=z^{\kappa}(1-z)^{\beta} f(z)
$$

Dengan memasukkan persamaan (4) ke dalam persamaan (2) akan diperoleh persamaan diferensial orde dua fungsi hipergeometri yang dinyatakan sebagai

$$
z(1-z) \frac{d^{2} \phi}{d z^{2}}+(c-(a+b+1) z) \frac{d \phi}{d z}-a b \phi=0
$$

yang mula-mula diusulkan oleh Gau $\beta$ [2], nilai $\alpha$ dan $\beta$ dapat diperoleh dengan pemisalan atau substitusi parameter potensial dan energi atau dengan mengnolkan koefisien dari fungsi $\mathrm{z}$ pada pers. (5) pada suku terakhir. Bentuk penyelesaian pers (5) di sekitar titik $\mathrm{z}=0$ adalah polinomial hipergeometri yang dinyatakan sebagai [2]

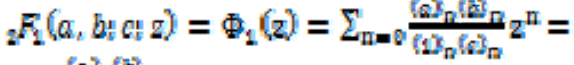

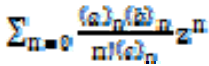

$(a)_{n}=a(a+1)(a+2)(a+3) \ldots \ldots(a+n-1)$

$$
\text { dan }(a)_{0}=1
$$

Penyelesaian persamaan diferensial fungsi hipergeometri yang dinyatakan pada persamaan (6) di atas mempunyai harga bila semua penyebut dari deret tersebut tidak nol, maka $\mathrm{c} \neq-\mathrm{n}$, dimana $\mathrm{n}=0,1,2,3,4, \ldots \ldots$.

Bila $a=-n$ atau $b=-n$,

maka penyelesaian yang berupa deret pada persamaan (6) menjadi terputus sehingga diperoleh penyelesaian yang berhingga yaitu polynomial pangkat $n$. Dari kondisi yang dinyatakan pada pers. (8) dapat diperoleh tingkat energi dari sistem.

3.2 Penyelesaian Persamaan Schrodinger potensial nonsentral Poschl-Teller termodifikasi plus Scarf II trigonometrik menggunakan metode hipergeometri

Persamaan Schrodinger tiga dimensi potensial non-sentral PTT plus SIIT dinyatakan sebagai

$$
\begin{aligned}
& -\frac{\hbar^{2}}{2 M}\left\{\frac{1}{r^{2}} \frac{\partial}{\partial r}\left(r^{2} \frac{\partial}{\partial r}\right)+\frac{1}{r^{2} \sin \theta} \frac{\partial}{\alpha \theta}\left(\sin \theta \frac{\partial}{\partial \theta}\right)+\right. \\
& \left.\frac{1}{\gamma^{2} \sin ^{2} \theta} \frac{\theta^{2}}{d \varphi^{2}}\right) \psi(r, \theta, \varphi)+\left\{\frac{n^{2}}{2 M}\left(\frac{k \ln -1)}{\sin ^{2} \alpha^{2}}-\frac{n(\theta+1)}{\cos ^{2} \gamma}\right)+\right.
\end{aligned}
$$

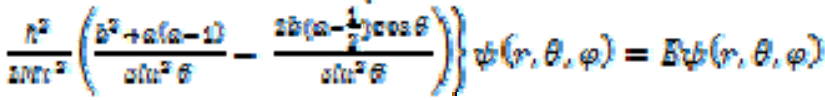

Pers. (9) diselesaikan dengan metode pemisahan variabel sehingga diperoleh tiga persamaan diferensial satu dimensi fungsi radial, fungsi sudut polar dan azimuthal yang dinyatakan sebagai

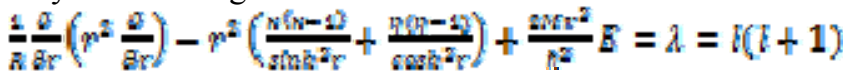

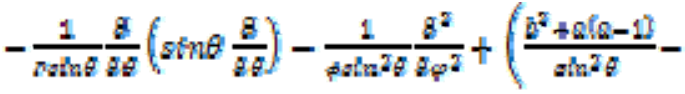

$$
\begin{aligned}
& \left.\frac{2 \pi\left(\alpha-\frac{1}{2} \operatorname{ses} \theta\right.}{\sin ^{2} \theta}\right)-\lambda-\varepsilon(\varepsilon+1) \\
& \frac{1}{\phi} \frac{g^{2}}{\delta \varphi^{2}}=-m^{2}
\end{aligned}
$$

\subsubsection{Penyelesaian pers. Schrodinger bagian radial}

Untuk menyelesaikan pers. (10a) kita misalkan $R=\frac{\gamma \mathrm{cr}}{\mathrm{r}}$ dan dengan menggunakan pendekatan $\frac{1}{\gamma^{2}} \cong\left(\alpha_{0}+\frac{1^{r}}{\sin ^{2} r}\right)$ dengan $d_{D}=\frac{1}{2}$ untuk faktor sentrifugal [Aldirch + Sameer] serta dengan melakukan substitusi variabel $\cosh ^{2} p=z$ pers. (10a) berubah menjadi

$$
\begin{aligned}
& z(1-z) \frac{g^{2} z}{g z^{2}}+\frac{1}{2}(1-2 z) \frac{g x}{g z}+\left\{\frac{\varepsilon^{2}}{4}-\frac{k(k-1)+3(x+1)}{4(1-z)}-\right. \\
& \left.\frac{n(g+1)}{4 z}\right) X=0
\end{aligned}
$$


dengan membuat permisalan bahwa $\frac{-\eta}{2}=\alpha, \quad \kappa^{\gamma}=2 \beta$ dimana Pers. (12) merupakan PPH dan akan berubah menjadi persamaan diferensial hipergeometri seperti pada pers. (5) bila dimisalkan penyelesaian fungsi gelombangnya dinyatakan sebagai

$$
\chi=z^{\alpha}(1-z)^{q} f(z)
$$

Bila persamaan (13) dimasukkan ke dalam pers. diperoleh

$$
\begin{aligned}
& z(1-z) \frac{d^{2} f}{d z^{2}}+\left(\left(2 \alpha+\frac{1}{2}\right)-(2 \alpha+2 \beta+1) z\right) \frac{d f}{d z} \\
& \frac{z^{2}}{4}+\frac{2 g(z \alpha-1)}{4(1-z)}+\frac{-2 \alpha(-2 \alpha+1)}{4 z}-(\alpha+\beta)^{2}-\frac{\kappa^{2}(\alpha-1)}{4(1-z)}- \\
& \frac{2(p+1)}{4 z} y=0
\end{aligned}
$$

dengan $\kappa(\kappa-1)+\varepsilon(t+1)=\kappa^{5}\left(\kappa^{t}-1\right)$

Persamaan (14) akan tereduksi menjadi persamaan hipergeometri bila koefisien dari $\frac{1}{4(1-z)}$ dan $\frac{1}{4 z}$ pada suku terakhir persamaan (14) dinolkan sehingga diperoleh

$$
\begin{aligned}
& 2 \beta(2 \beta-1)=\kappa(\kappa-1) \\
& -2 \alpha(-2 \alpha+1)=\eta(n+1) \quad-2 \alpha=\eta
\end{aligned}
$$

dan persamaan (14) tereduksi menjadi

$$
\begin{aligned}
& z(1-z) \frac{d^{2} f}{d z^{2}}+\left(\left(2 \alpha+\frac{1}{2}\right)-(2 \alpha+2 \beta+1) z\right) \frac{d f}{d z} \\
& \frac{\varepsilon^{2}}{4}-(\alpha+\beta)^{2} y-0
\end{aligned}
$$

Pers (16) merupakan persamaan diferensial fungsi Hypergeometry yang penyelesaiannya dinyatakan sebagai

$f(z)=F_{2} F_{1}\left(a^{*}, b^{*}, c^{*}, z\right)$

dimana

$a^{*}=\alpha+\beta+\frac{\varepsilon}{2}, \quad b^{*}=\alpha+\beta-\frac{\varepsilon}{2} \quad$ dan $\quad c^{*}=2 \alpha+\frac{1}{2}$

Pers (17) yang merupakan polinomial hipergeometri akan terputus bila memenuhi pers. (8), $a^{\prime}=-n$ atau $b^{*}=-n$ sehingga diperoleh deret berhingga. Jadi bila kita pilih harga $a^{\prime}=-n$ maka dengan menggunakan persamaan (8) dan (18) diperoleh $-\frac{n}{2}+\frac{k^{\prime}}{2} \quad+\frac{E}{2}=-n$ atau $e=\eta-\kappa^{t}-2 n$ dan dari persamaan ini diperoleh spectrum energi untuk potensial Poshcl-Teller termodifikasi yaitu

$$
\begin{aligned}
& E_{n}=-\frac{n^{2}}{2 n}\left(n-\kappa^{2}-2 n\right)^{2}= \\
& -\frac{n^{2}}{2 n}\left(n-\sqrt{\kappa(\kappa-1)+E(n+1)+\frac{1}{4}}-\frac{1}{2}-2 n\right)^{2}
\end{aligned}
$$

Pada kondisi khusus dimana $k=0$ pers. (19) berubah menjadi spektrum energi untuk potensial Poschl-Teller termodifikasi yaitu

$$
E_{i:}=-\frac{\pi^{2}}{2 n}(n-\kappa-2 n)^{2}
$$

Penyelesaian fungsi gelombang bagian radial diperoleh dengan memasukkan pers (15), dan (17) ke dalam pers (13) yaitu
$\chi(r)=C(\cosh r)^{-r}$

$\left(\sinh ^{2} r\right)^{K^{6}} \quad{ }_{2} F_{1}\left(-n-\eta+\kappa^{r}+n_{t}-\eta+\frac{1}{2} \cosh ^{2} r\right)$

Fungsi gelombang tingkat dasar diperoleh dari pers. (21) untuk $\mathrm{n}=0$

$I_{v}=G(\mathrm{owhh} r)^{-\eta}(\mathrm{ohnh} r)^{\mathrm{kr}}$

dengan $\kappa^{x}=\sqrt{\left(\kappa-\frac{1}{2}\right)^{2}+t(t+1)}+\frac{1}{2}$

\subsubsection{Penyelesaian persamaan Schrodinger bagian sudut}

Persamaan Schrodinger bagian sudut pada pers. (10b) dapat dinyatakan sebagai persamaan Schrodinger satu dimensi secara eksplisit dengan memisalkan bahwa $R=\frac{P}{\sqrt{\operatorname{mat}}}$ sehingga diperoleh

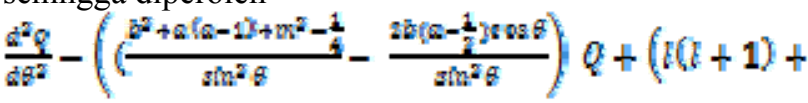

1) $Q=Q$

Untuk menyelesaikan persamaan (23), kita lakukan substitusi variabel $\cos \theta=1-2 \mathrm{~s}$ sehingga pers. (23) berubah menjadi

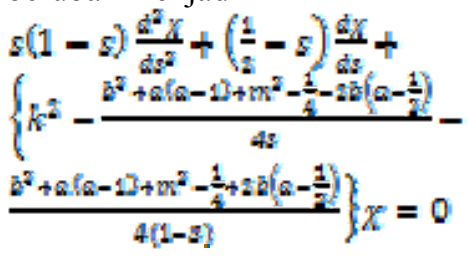

dengan $2(l+1)+\frac{4}{4}=k^{2}$

Persamaan (24) diselesaikan dengan menggunakan metode hipergeometri dengan memisalkan penyelesaian fungsi gelombangnya dinyatakan sebagai

$$
Q=s^{\alpha}(1-s)^{\theta} f(s)
$$

Dengan memasukkan persamaan (25) ke dalam persamaan (24) diperoleh

$$
\begin{aligned}
& s(1-z) \frac{d^{2} f}{d \xi^{2}}+\left(\left(2 \alpha+\frac{1}{2}\right)-(2 \alpha+2 \beta+1) \varepsilon\right) \frac{d f}{d z}-\{(\alpha+
\end{aligned}
$$

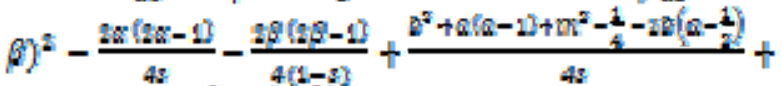

$$
\begin{aligned}
& \left.\frac{b^{2}+a(a-1)^{2}+k^{2}-\frac{1}{4}+2 a\left(a-\frac{1}{2}\right)^{2}}{4(a)}-k^{2}\right] f=0
\end{aligned}
$$

Persamaan (26) menjadi persamaan diferensial orde dua fungsi hipergeometri bila koefisien suku yang berpenyebut $4 z$ dan 4(1-z) di nolkan sehingga diperoleh

$$
b^{2}+a(\alpha-1)+m x^{2}-\frac{1}{4}+2 b\left(a-\frac{1}{2}\right)=2 \beta(2 \beta-1)
$$

(27a)

$b^{2}+a(\alpha-1)+m \sigma^{2}-\frac{1}{4}-2 b\left(a-\frac{1}{2}\right)=2 \alpha(2 \alpha-1)$

(27b)

dan pers (26) berubah menjadi

$$
\begin{aligned}
& s(1-\varepsilon) \frac{d^{2} f}{d g^{2}}+\left(\left(2 \alpha+\frac{1}{2}\right)-(2 \alpha+2 \beta+1) \varepsilon\right) \frac{d f}{d z} \\
& -\left\{(\alpha+\beta)^{2}-k^{2}\right\} f=0
\end{aligned}
$$


Dari pers. (27a) dan (27b) diperoleh

$\beta=\frac{\sqrt{\left(E+a \frac{1}{2}\right)^{2}+m^{2} \frac{1}{4}}+\frac{1}{2}}{2}$ dan $\quad \alpha=\frac{\sqrt{\left(E+a+\frac{1}{2}\right)^{2}+m^{2} \frac{1}{4}}+\frac{1}{2}}{2}$

Dengan mengaplikasikan prasyarat pada pers. (8) untuk pers. (28) diperoleh

$(\omega+\beta)+k=-\pi$, atau $(\omega+\beta)-k=-v$

Dengan memilih harga $\alpha^{x}=(\alpha+\beta)-k=-n$ pada pers. (30) dan dengan mengkombinasikannya dengan pers. (29) diperoleh

$k=k+\frac{1}{2}=\frac{\sqrt{\left(\bar{\alpha}+a-\frac{1}{2}\right)^{2}+n^{2}-\frac{1}{4}}+\frac{1}{2}}{2}+\frac{\sqrt{\left(\bar{\alpha}-\alpha+\frac{1}{2}\right)^{2}+n^{2}-\frac{1}{4}}+\frac{1}{2}}{2}+n$

Harga 1 pada pers. (31) digunakan untuk menghitung spektrum energi pada pers. (19) dan fungsi gelombang radial pada pers.(21). Dengan memasukkan pers. (29) ke dalam pers. (25) diperoleh

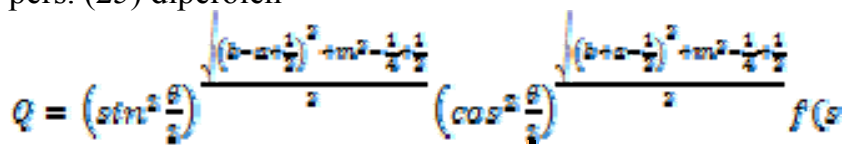

dengan $f(g)=2, F_{1}\left(-n_{2}-n+2 \kappa_{n} 2 \alpha+\frac{1}{2} \sin ^{2} \frac{\theta}{2}\right)$

Dari pers. (31) diperoleh fungsi gelombang fungsi sudut yang dinyatakan sebagai

atau

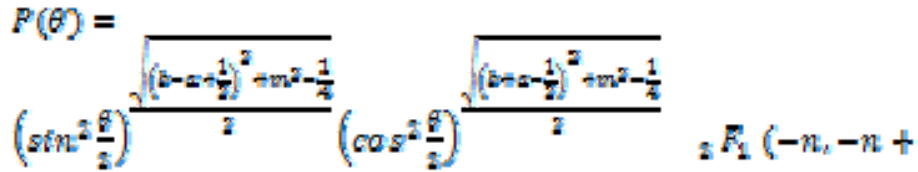

$2 k+2 \alpha+\frac{1}{2}, \sin 2 \frac{6}{2}$

Fungsi gelombang lengkap tak ternormalisasi untuk potensial non-sentral Poschl-Teller hiperbolik plus Scarf II trigonometrik diperoleh dari pers. (11), (21) dan (33) yang dinyatakan sebagai
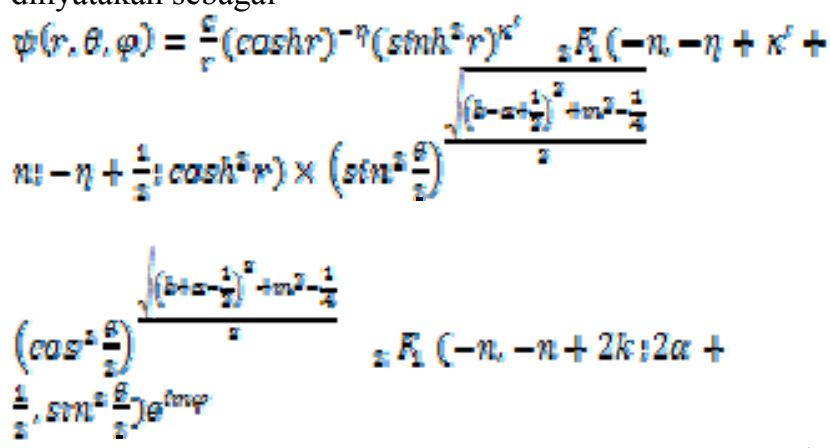

\section{KESIMPULAN}

Spektrum energi dan fungsi gelombang untuk potensial nonsentral Poschl-Teller hiperbolik dan Scarf II trigonometrik dianalisa dengan menggunakan persamaan hipergeometrik. Spektrum dan fungsi gelombang bagian radial diperoleh dari persamaan Schrodinger bagian radial dan hasilnya hanya bersifat pendekatan karena hadirnya faktor sentrifugal. Fungsi gelombang bagia sudut polar dan bilangan kuantum orbital diperoleh dari persamaan Schrodinger bagian sudut polar. Spektrum energi tereduksi menjadi energi PoschlTeller hiperbolik apabila bilangan kuantum orbital menjadi nol, demikian juga fungsi gelombang bagian radialnya. Apabila potensial non-sentral Scarf II absent fungsi gelombang sudut tereduksi menjadi fungsi gelombang bola harmonik.

\section{UCAPAN TERIMA KASIH}

Penelitian ini didukung oleh Hibah Pascasarjana 2340/UN27.10/PG/2012

\section{PUSTAKA}

[1] Suparmi. 2011. Mekanika Kuantum II. Jurusan Fisika Fakultas MIPA Universitas Sebelas Maret Surakarta.

[2] Greiner, W. Quantum Mechanics An Introduction, S.Springer-Verlag, Berlin Heidilberg, 1992.

[3] Suparmi. 1992. Semiclassical Quantization Rules in Supersymetric Quantum Mechanics: Desrtation. SUNNY The University at Albany Physics Departement.

[4] C S Jia, Y. Sun, Y. Li, Complexified Pöschl-Teller II potential model,Physics Letters A 305 (2002) 231-238.

[5] A. Suparmi, C. Cari, J. Handhika, C. Yanuarief, H. Marini "Approximate Solution of Schrodinger Equation for Modified Poschl-Teller plus Trigonometric RosenMorse Non-Central potentials in terms of Finite Romanovski Polynomials", IOSR-JAP, Vol. 2 Issue 2 ISSN 2278-4861 (2012) pp 43-51, DOI:109790/48610224351 .

[6] Y. Xu, S. He and C.S. Jia, Approximate analytical solutions of the Klein-Gordon equation with the PoschlTeller potential including the centrifugal term, Phys. Scr. 81, 2010, 045001

[7] H. Hassan, Y. B. Hoda, L. Liang-Liang, Approximate Analytical Solutions to the Generalized Pöschl-Teller Potential in DDimensions, CHIN. PHYS. LETT29 (2), 2012, 020303.

[8] D.E Alvarez -Castillo and M. Kirbach, Exact Spectrum and Wave Functions of The Hyperbolic Scarf Potential in Terms of Finite Romanovski Polynomials,Rev. Mex. Fis.E 53(2),2007,143-154. $\quad$ http://dx.doi.org/10.1063/ 1.529565 (8 pages)

[9] A. Arda, R. Sever, Approximate 1-State Solutions of the Klein-Gordon Equation for Generalized Woods-Saxon Potential With Position Dependent Mass, Int. J. Mod.Phys.A24,(2009)3985.Doi:10.4025/actascitechnol.v 34i2. 13323

[10] Cari dan Suparmi, "Approximate Solution of Schrodinger Equation for Hulthen Potential plus Eckart Potential with Centrifugal Term in terms of Finite Romanovski Polynomials", IJAPM, Vol.2, No 3, IACSIT Publishing, Singapore (2012), ISSN 2010-362X 
[11] Antomi Saregar, A. Suparmi, C. Cari, H Yuliani. "Analysis of Energy Specta and Wave Function of trigonometric Poschl-Teller Plus Rosen-Morse Noncentral Potential Using Supersymetric Quantum Mechanics Approac".Research Innventy ISSN:22784721, Vol.2 Issue 3 (February 2013), PP 14-26.

[12] C. Cari and A Suparmi "Approximate Solution of Schrodinger Equation for Trigonometric Scarf Potential with Poschl-Teller Non-Central potential Using NU Method", IOSR-JAP, Vol. 2 Issue 3 ISSN
2278-4861 (2012) pp 13-23, DOI:109790/48610231323

[13] A. F. Nikiforov, and V. B. Uvarov, Special Functions of Mathematical Physics .Birkhauser, Basel, 1988.

[14] Khare A., Sukharme U. Jour.Phy .A26 (1993).

[15] Flugge, Siegfried. Practical Quantum Mechanics II, Springer-Verlag, New York, 1987. 